Bianca Maria Liquidato', Rita de Cássia Soler ${ }^{2}$, Ivo Bussoloti Filbo ${ }^{3}$

\section{Evaluation of the concordance of sialometry and salivary glands scintigraphy in dry mouth patients}

Key words: xerostomia, salivary glands, saliva, diagnosis.

\section{Summary}

\begin{abstract}
I (to evaluate dry mouth patients, especially the ones with Sjögren's Syndrome, to whom these tests are part of classification criteria for scientific studies. Aim: Thus, the concordance between results of sialometry and salivary glands scintigraphy was evaluated; if positive, it would enable the choice of one or the other for diagnosis. Patients and Method: Seventytwo dry mouth patients were divided into non-Sjögren's Syndrome group, primary Sjögren's Syndrome group and secondary Sjögren's Syndrome group. The concordance among sialometry and scintigraphy results was evaluated by Kappa test. Results: It was observed that their concordance was equal or near to zero. Conclusion: It is not possible to make a choice between these tests and both should be performed.
\end{abstract}

${ }^{1} \mathrm{PhD}$ in otolaryngology from the F.C.M. Santa Casa de São Paulo - Prof. Instructor of the Morphology Department - F.C.M. Santa Casa de São Paulo ${ }^{2} \mathrm{PhD}$ in otolaryngology from the F.C.M. Santa Casa de São Paulo - Prof. Instructor of the Hospital Nossa Sra. de Lourdes

$3 \mathrm{PhD}$ in otolaryngology from the UNIFESP - Assistant Professor of the Otolaryngology department - Faculdade de Ciências Médicas da Santa Casa de São Paulo. Otolaryngology Department of the Medical Sciences School of the Santa Casa de São Paulo Mailing address: Bianca Maria Liquidato Rua Turiaçú 390 cj 15 Perdizes São Paulo SP 05005-001 Tel. e Fax: (11)3675-1527

Paper submitted to the ABORL-CCF SGP (Management Publications System) on December 11, 2004, and accepted for publication on May $23^{\text {rd }}$, 2005. 


\section{INTRODUCTION}

The assessment of dry mouth complaining patients involves a number of questions, both to confirm the complaint as well as to try and define one etiology ${ }^{1,2}$.

The oral cavity exam may bring important information about the oral mucosa situation and the possible complications of salivary secretion reduction ${ }^{3,4}$.

Besides the clinical evaluation, a number of tests should be performed in order to determine salivary flow alterations $s^{1,5}$. Sjögren's syndrome is among the various causes of dry mouth ${ }^{1,2}$, and once there is no test to ascertain its diagnosis, there are classification criteria used to include patients in the scientific studies ${ }^{6,7}$.

The criteria used to classify both primary and secondary Sjögren's syndrome, has been broadly discussed in the international literature.

Such discussion involves not only the set of criteria to be used, in other words, those published by many groups, but also the ones from Copenhagen, San Diego, the Greek, the Japanese and the ones from the European Community Study Group/American-European Consensus, but also the tests that should be carried out ${ }^{6-9}$. At any rate, most sets of criteria provide us with options as to the tests to be carried out in order to fulfill a certain item of a set of criteria.

The European Community Study Group tried to validate a number of tests that had their specificity and sensitivity tested in this way ${ }^{10,11}$.

Thus, the ones with the best performance were included as part of this set of criteria.

In order to evaluate the involvement of the greater salivary glands, they chose salivary gland scintigraphy; parotid gland sialography and the non-stimulated salivary flow sialometry ${ }^{9-14}$.

Among them, both the sialometry ${ }^{15-17}$ and the scintigraphy ${ }^{18,19}$ assess the gland function, not only its image.

When altered, any of these tests fulfill the criterion ${ }^{13,14}$. Sialometry is a simple, low cost test, and of easy execution as long as the technique is standardized ${ }^{16}$.

Scintigraphy bears advantages that include the saliva quantitative analysis throughout the evaluation of radiopharmaceutical build up and salivary escape, which may correctly reflect the functional alterations and bring information about obstructive clogging of the salivary gland.

It may also detect early stages of salivary gland involvement ${ }^{18-20}$. Because sialometry and scintigraphy are easily executed tests and provide information about the glandular function, often times they are preferred over parotid sialography, which is also a more invasive type of test.

For these reasons and also because of the great current cost concern, let alone the major technological innovations, we tried to assess if there would be an correspondence between the salivary gland sialometry and the scintigraphy so that, if present, we could chose one of the two tests.

\section{MATERIALS AND METHODS}

All dry mouth patients who came to the Otolaryngology Department of the Santa Casa de São Paulo, were then referred to the stomatology outpatient ward of the institution.

From January 1997 until December 2003, 72 patients with this complaint were clinically assessed and underwent diagnostic evaluation and classification, based on the criteria established at the American-European Consensus ${ }^{14}$ (Chart 1).

Based on such criteria, these patients were divided in 2 groups: one group that did not have Sjögren syndrome (NSS) and a group with Sjögren syndrome (SS).

The Sjögren syndrome group was further divided in 2 subgroups: with primary Sjögren syndrome (SSp) and secondary Sjögren syndrome (SSsec).

In order to classify the patients with primary Sjögren syndrome it was necessary to have 4 of the 6 items, items IV (histopathology) or VI (autoantibodies) were mandatory.

As far as the secondary Sjögren syndrome patients classification is concerned, this was done with the presence of either item I or II, plus any other among items III, IV and V (Chart 1). Exclusion criteria for Sjögren syndrome classification were previous head and neck radiotherapy; pre-existent lymphoma; sarcoidosis; graft versus host disease; anti-cholinergic drug use.

There was also one Wegener granulomatosis patient that was excluded.

Criterion V, assessment of major salivary gland involvement encompasses, as previously mentioned, an altered salivary glands sialometry or scintigraphy, or parotid sialography.

Non stimulated sialometry was carried out through the saliva collection technique using two cotton balls which had been previously weighed together with the universal collecting $80 \mathrm{ml}$ jar, in a digital scale.

Patients were advised to swallow all the saliva they had in their oral cavity and the cotton balls were then placed on the mouth floor, close to the gingival border, where they remained for 2 minutes.

After this time span the whole set was again weighed.

The weight difference was directly changed from $\mathrm{g} / \mathrm{min}$ into $\mathrm{ml} / \mathrm{minute}$ and was considered as altered with values below $0.1 \mathrm{ml} /$ minute.

The salivary gland scintigraphy was carried out assessing sodium pertechnetate technetium uptake in the $15 \mathrm{mCi}$ dose and its subsequent clearance after salivary 
Chart 1. Sjögren syndrome classification criteria

I. Ocular symptoms, positive answer for at least one of the following questions:

1. Have you had dry eyes daily for more than 3 months?

\section{Do you have a recurrent feeling of sand in your eyes?}

3. Do use artificial tears more than three times daily?

II. Oral symptoms, positive answer to at least one of the following questions:

\section{Have you had daily symptoms of dry mouth for more than three months?}

2. Have you had recurrent or persistent salivary gland enlargement as an adult?

3. Do you frequently drink something in order to help you swallow dry food?

III. Ocular involvement signs: positive result for one of the following two tests:

- Schirmer test I (< or $=5 \mathrm{~mm}$ in $5 \mathrm{~min}$ );

- Bengal Pink or other dye test $(>$ or $=$ to 4$)$.

IV. histopathology: one or more foci (cluster of 50 or more inflammatory cells) by $4 \mathrm{~mm} 2$ of glandular tissue in minor salivary gland biopsy.

V. Salivary gland involvement, positive result for one of the following diagnostic tests:

- Non-stimulated total salivary flow sialometry $<$ or $=$ to $1.5 \mathrm{ml}$ in 15 minutes;

- Parotid Sialography showing diffuse sialectasis, without evidence of obstruction of the larger ducts;

- Salivary scintigraphy with uptake delay, reduction in the concentration and/or delay in tracer secretion.

VI. Auto-antibodies, presence of one or both: Anti-Ro (SS-A) or anti-La (SS-B) antibodies

Fonte: VITALI et al (2002).

stimulation with $8 \mathrm{ml}$ of lemon juice on the tongue dorsum, 20 minutes after the radiopharmaceutical injection.

Scintigraphies with delayed uptake; reduced concentration and/or delay in the tracer secretion were considered altered. The statistical methodology used was the Kappa measure, which is an correspondence measure where the 0 value indicates no correspondence and the 1 value indicates total correspondence.
Kappa was then calculated for the NSS, SSp, and SSsec groups and for all the patients.

In order to check whether the correspondence was reasonable, a statistical test was carried out to assess Kappa significance.

The significance index used was 5\%. The Institution Ethics Committee approved such research.

\section{RESULTS}

The Kappa values found were different from zero for all cases and for the NSS group, however for the SSp and SSsec groups, such values were equal to zero (Table 1). In groups where the correspondence index was different from zero, the values were very low.

Table 1. Kappa results calculated for the different groups

\begin{tabular}{lccc}
\hline & Kappa & Standard error & $p$ \\
\hline All cases & 0,22 & 0,09 & 0,018 \\
NSS Group & 0,36 & 0,11 & 0,003 \\
SSp Group & $-0,11$ & 0,10 & 0,506 \\
SSsec Group & $-0,23$ & 0,21 & 0,236
\end{tabular}

NSS = non-Sjögren syndrome; $S S p=$ primary Sjögren syn-

drome; SSsec = secondary Sjögren syndrome

\section{DISCUSSION}

According to the current attempt to reduce costs, if it were possible to choose between one of the tests, the choice would be the sialometry, because it is a low cost test that does not expose the patient to radiation.

The very fact of the Kappa index that assesses the correspondence of the test results be equal to zero or very low, indicates that we may not choose one of the tests only.

This low or absent correspondence may be due to the fact that sialometry assesses glandular function only, while scintigraphy also assesses radioisotope uptake by the gland, that may be influenced by circulatory alterations.

At any rate, both tests may be subject to variations related to fluctuations in the quantity of saliva produced.

This fact alone confirms the need to use diagnostic criteria that involve more then one test to assess the involvement of the greater salivary glands.

\section{CONCLUSION}

Both sialometry and scintigraphy should be carried out in order to assess the involvement of salivary glands in patients complaining of dry mouth, specially in Sjögren 
syndrome patients, since one can not replace the other because of a lack of correspondence among their results.

\section{BIBLIOGRAPHY}

1. FOX PC. Differentiation of dry mouth etiology. Adv Dent Res 1996; 10:13-16.

2. BELL M, ASKARI A, BOOKMAN A, FRYDRYCH S, LAMONT J, MCCOMB J, et al. Sjögren's syndrome: a critical review of clinical management. J Rheumatol 1999; 26:2051-2061.

3. CROCKETT DN. Xerostomia: the missing diagnosis? Aust Dent J 1993; 38:114-118.

4. DANIELS TE. Evaluation, differential diagnosis, and treatment of xerostomia. J Rheumatol 2000; 61(Suppl):6-10.

5. FOX PC, BUSCH KA, BAUM BJ. Subjective reports of xerostomia and objective measures of salivary gland performance. J Am Dent Assoc 1987; 115:581-584.

6. MANTHORPE R. New criteria for diagnosing Sjögren's syndrome: a step forward? - or... .Scand J Rheumatol 2001; 115(Suppl):14-22.

7. MANTHORPE R. Sjögren's syndrome criteria. American-European and Japanese Groups' criteria compared and contrasted. Ann Rheum Dis 2002; 61:482-484.

8. FOX RI, ROBINSON CA, CURD JG, KOZIN F, HOWELL FV. Sjögren's Syndrome: Proposed criteria for classification. Arthritis Rheum 1986; 29:577-585.

9. VITALI C, BOMBARDIERI S, JONSSON R, MOUTSOPOULOS HM, ALEXANDER EL, CARSONS SE, THE EUROPEAN STUDY GROUP ON CLASSIFICATION CRITERIA FOR SJÖGREN'S SYNDROME. Classification criteria for Sjögren's syndrome: a revised version of the European criteria proposed by the American-European Consensus Group. Ann Rheum Dis 2002; 61:554-558.

10. VITALI C, BOMBARDIERI S, MOUTSOPOULOS HM, BALESTRIERI G, BENCIVELLI W, BERNSTEIN RM, et al. Preliminary criteria for Sjögren's Syndrome. Results of a prospective concerted action supported by the European Community. Arthritis Rheum 1993; 36:340-347.

11. VITALI C, MOUTSOPOULOS HM, BOMBARDIERI S, THE EUROPEAN COMMUNITY STUDY GROUP ON DIAGNOSTIC CRITERIA FOR
SJÖGREN'S SYNDROME. The European Community Study Group on Diagnostic Criteria for Sjögren's Syndrome. Sensitivity and specificity of tests for ocular and oral involvement in Sjögren's Syndrome. Ann Rheum Dis 1994; 53:637-647.

12. VITALI C, BOMBARDIERI S, MOUTSOPOULOS HM, COLL J, GERLI R, HATRON PY, THE EUROPEAN COMMUNITY STUDY GROUP ON DIAGNOSTIC CRITERIA FOR SJÖGREN'S SYNDROME. Assessment of the European classification criteria for Sjögren's syndrome in a series of clinically defined cases: results of a prospective multicentre study. Ann Rheum Dis 1996; 55: 116-121.

13. VITALI C, BOMBARDIERI S. The diagnosis of Sjögren's syndrome: definition and validation of classification criteria for this disorder. Ann Med Interne1998; 149:12-16.

14. VITALI C, BOMBARDIERI S, MOUTSOPOULOS HM, THE EUROPEAN STUDY GROUP FOR THE CLASSIFICATION CRITERIA FOR SJÖGREN'S SYNDROME. A proposal for modification of the European classification criteria for Sjögren's syndrome. Clin Exp Rheumatol 2000; $18: 118$

15. NAVAZESH M, CHISTENSEN CM. A comparison of whole mouth resting and stimulated salivary measurement procedures. J Dent Res 1982; 61:1158-1162

16. PUPO DB, BUSSOLOTI FILHO I, LIQUIDATO BM, KORN GP. PrOposta de um método prático de sialometria. Rev Bras Otorrinolaringol 2002; 68:219-22.

17. SÁNCHEZ-GUERRERO J, AGUIRRE-GARCIA E, PÉREZ-DOSAL MR, KRAUS A, CARDIEL MH, SOTO-ROJAS AE. The wafer test: a semi-quantitative test to screen for xerostomia. Rheumatology 2002; 41:381-389

18. PARRAGO J, RAIN JD, BROCHERIOU C, ROCHER F. Scintigraphy of the salivary glands in Sjögren's syndrome. J Clin Pathol 1987; 40:1463-1467.

19. KAGAMI H, HAYASHI T, SHIGETOMI T, UEDA M. Assessment of the effects of aging and medication on salivary gland function in patients with xerostomia using 99mTc-scintigraphy. Nagoya J Med Sci $1995 ; 58: 149-155$

20. KAO CH, TSAI SC, SUN SS. Scintigrafic evidence of poor salivary function in type 2 diabetes. Diabetes care 2001; 24:952-953. 